\title{
Febre reumática - patogênese e vacina
}

\section{Rheumatic fever - pathogenesis and vaccine}

\author{
Karine Marafigo De Amicis ${ }^{1,2}$, Nathália Moreira Santos ${ }^{1,2}$, Luiza Guilherme ${ }^{1,2}$
}

De Amicis KM, Santos NM, Guilherme L. Febre reumática - patogênese e vacina / Rheumatic fever - pathogenesis and vaccine. Rev Med (São Paulo). 2012;91(4):253-60.

\begin{abstract}
RESUMO: Há um amplo espectro de doenças causadas por estreptococos do grupo A (GAS), e estas são consideradas um problema de saúde pública em países em desenvolvimento, com aproximadamente 600 milhões de casos/ano. As infecções causadas por GAS podem ocasionar doenças invasivas como faringite e pioderma com seqüelas auto-imunes graves como a febre reumática (FR) e glomerulonefrite. A FR acomete principalmente crianças e jovens, inicia com poliartrite na maioria dos casos. Tem como sequelas principais a coreia de Sydenham e a doença reumática cardíaca (DRC), considerada a forma mais grave da doença e caracterizada por lesões cardíacas valvares progressivas e permanentes, que necessitam de cirurgias cardíacas para correção valvular, com alto custo para os Sistemas de Saúde, no mundo. A presente revisão descreve os principais mecanismos desencadeadores das lesões reumáticas no coração e o desenvolvimento da vacina contra o Streptococcus pyogenes para prevenção das principais sequelas decorrentes das streptococcias.
\end{abstract}

DESCRITORES: Febre reumática, Doença reumática cardíaca, Streptococcus pyogenes, Vacina.
ABSTRACT: Group A streptococci (GAS) infections are considered a public health problem in developing countries, with about 600 million cases per year and are responsible for an wide spectrum of diseases, mainly invasive diseases as pharyngitis and pyoderma that lead to rheumatic fever (RF) and glomerulonephritis autoimmune sequelae. RF affects children and young adults, and presents different manifestations such as rheumatic heart disease (RHD), Sydenham chorea, erythema marginatum, subcutaneous nodules. RHD is considered the most serious complications leading to cardiac valvular lesions characterized by progressive and permanent heart-valve damage, which entails high cost to the Healthy System around the world. In the present review we described the mechanisms that lead to rheumatic heart lesions and the development of a vaccine against Streptococcus pyogenes.

KEYWORDS: Rheumatic fever, Rheumatic heart disease, Streptococcus pyogenes, Vaccine.

1. Instituto do Coração (InCor), Universidade de São Paulo, Faculdade de Medicina, São Paulo, Brasil.

2. Instituto de Investigação em Imunologia, Institutos Nacionais de Ciência e Tecnologia, Universidade de São Paulo, São Paulo, Brasil.

Endereço para correspondência: Laboratório de Imunologia do InCor. Avenida Dr. Enéas de Carvalho Aguiar, 44, 9º andar, bloco 2 - Cerqueira César. CEP05403-900. São Paulo, SP. e-mail: luizagui @usp.br 


\section{INTRODUÇÃO}

A Febre Reumática (FR) e a Doença Reumática Cardíaca (DRC) são seqüelas autoimunes pósestreptocócicas que podem ocorrer tardiamente em indivíduos geneticamente suscetíveis à infecção por Streptococcus pyogenes. Causam sérios danos às válvulas cardíacas podendo levar o indivíduo a óbito por insuficiência cardíaca ${ }^{1}$.

A FR acomete principalmente crianças e jovens adultos, que podem apresentar diversas manifestações, sendo a DRC a seqüela mais grave, caracterizada por lesões cardíacas valvares progressivas e permanentes ${ }^{2}$. Pode afetar o pericárdio, o miocárdio e o endocárdio. A pericardite e a miocardite apresentam bom prognóstico com resolução em até 30 dias após a infecção. Já a endocardite, promove lesões de válvulas, principalmente mitral e aórtica, que pode levar ao quadro de insuficiência cardíaca ${ }^{3}$.

As manifestações e sinais clínicos principais da FR são: poliartrite migratória, Coréia de Sydenham, eritema marginatum, cardite e nódulos subcutâneos ${ }^{4}$.

A poliartrite é a manifestação inicial e mais comum da FR, afetando aproximadamente $90 \%$ dos pacientes. Já a DRC é a sequela mais grave. Inicia-se de 4-8 semanas após a infecção pelo estreptococo do grupo A em $30-45 \%$ dos pacientes 5 .

O S. pyogenes é o agente causador de várias doenças, que vão desde infecções superficiais até doenças invasivas graves e seqüelas debilitantes, dentre elas a FR e a DRC. Entre as doenças superficiais, as mais comuns são a Faringite e o Impetigo e entre as invasivas podemos destacar a Síndrome do Choque Tóxico Estreptocócico (STSS) e a Fasciíte Necrotizante ${ }^{6}$.

O Streptococcus pyogenes é um patógeno estritamente humano. Foi primeiramente caracterizado por Rebecca Lancefield como Estreptococo Betahemolítico do Grupo A ou GAS (GAS, do inglês Group A Streptococcus) porque apresenta em sua parede o carboidrato $\mathrm{C}$, um polímero de $\mathrm{N}$-acetil- $\beta-$ D-glicosamina e ramnose ${ }^{7}$.

O S. pyogenes é uma bactéria extracelular, em forma de cocos agrupados em cadeia. Possui característica Gram positiva quando corada pelo método de Gram e capacidade $\beta$-hemolítica quando cultivado em ágar sangue. As colônias podem ser altamente mucóides ou secas e catalase negativas ${ }^{8}$.

É uma bactéria altamente patogênica, mas no momento da colonização do tecido hospedeiro encontra uma variedade de forças biológicas, mecânicas e químicas que devem ser vencidas para que possa aderir ao epitélio da orofaringe e causar a doença. A fixação do GAS às células da orofaringe ou da pele é o passo inicial mais importante na colonização do hospedeiro para a produção da doença. Os mecanismos de aderência do estreptococo do grupo $A$ tem a função de adesão aos tecidos do hospedeiro e de evitar a remoção pelo muco, pelo fluxo de saliva ou pelos mecanismos de esfoliação epitelial. Seus mecanismos de adesão específica permitem a competição entre a microbiota humana e o GAS por sítios no tecido onde a microbiota vive'.

Além disso, o S. pyogenes produz e secreta fatores de virulência que estão envolvidos na patogênese do choque tóxico estreptocócico, na invasão da pele e tecidos e na fascí́te necrotizante que são as exotoxinas pirogênicas capazes de modular o sistema imunológico. As exotoxinas agem como superantígenos, interagindo com as moléculas do complexo principal de histocompatibilidade (MHC) de classe II ativando inespecificamente um número massivo de células $T$. Esta ativação libera uma grande quantidade de interleucinas e outras citocinas inflamatórias como o TNF- $\alpha$ e o IFN- $\gamma$ que são potentes mediadores da resposta imunológica e inflamação que contribuem para o estabelecimento da doença estreptocócica ${ }^{9}$.

O hospedeiro tem várias armas imunológicas contra patógenos. As proteínas do sistema complemento desempenham um papel fundamental na resposta imune inata contra as bactérias. Essas proteínas cobrem a bactéria agindo como opsoninas para facilitar a fagocitose e geram substâncias que atraem fagócitos para o sítio de infecção. Ao longo de sua evolução, o S. pyogenes desenvolveu estratégias para escapar da resposta do sistema complemento através da produção de inibidores e ligando à sua proteína os reguladores negativos deste sistema, como C3, C3b e Fator $\mathrm{H}$ como forma de inativar mecanismos de defesa do hospedeiro ${ }^{10}$.

As doenças sistêmicas causadas por GAS refletem as diversas habilidades do $S$. pyogenes de escapar da sua erradicação por defesas fagocíticas do sistema imune inato ${ }^{11}$ em indivíduos com predisposição genética, que é um fator de risco para o desenvolvimento da FR/DRC. A resposta imunológica contra o hospedeiro e antígenos estreptocócicos, assim como situação sócio-econômica e etnia também são descritos como fatores de risco para o desenvolvimento de FR/DRC ${ }^{12}$.

As seqüelas autoimunes pós-estreptocócicas resultam da produção de anticorpos e células $T$ autorreativas, que reconhecem epitopos da proteína $\mathrm{M}$ do $S$. pyogenes e proteínas do tecido cardíaco humano por reação cruzada devido ao 
mimetismo molecular entre proteínas humanas e da bactéria ${ }^{13}$, resultante de homologia de sequência de aminoácidos, ou de carga ou de conformação da proteína. Na patogênese de doenças autoimunes, como por exemplo, a FR/DRC o mimetismo molecular é o principal mecanismo desencadeador do reconhecimento de sequências de aminoácidos de proteínas do patógeno e do organismo hospedeiro por anticorpos e/ou células T específicas ${ }^{14}$.

A proteína M é descrita como um dos principais antígenos da bactéria ${ }^{15}$. Apresenta-se como um conjunto de fibrilas que se extendem à superfície da bactéria, dispostas em duas cadeias polipeptídicas em alfa-hélice dupla, coiled-coil. É constituída por aproximadamente 450 resíduos de aminoácidos divididos em blocos de repetições, distribuídos em quatro regiões $(A, B, C$ e $D)$. A porção $N$-terminal (regiões $A$ e B) é a mais polimórfica e as diferenças nos primeiros 150 resíduos de aminoácidos da região A permitem classificar os diferentes sorotipos de $S$. pyogenes ${ }^{16,17}$. Atualmente existem mais de 225 tipos $\mathrm{M}$ e mais de 450 subtipos diferentes de acordo com o Centers for Disease Control and Prevention (CDC), dados disponíveis em http://www.cdc.gov/ncidod/ biotech/strep/strepblast.htm. Os blocos de repetição nesta região não aparecem em mesmo número em todas as cepas ou podem não apresentar algumas regiões, dando versatilidade a estas proteínas ${ }^{18}$.

Por outro lado, a porção C-terminal (regiões C e D) é altamente conservada e é responsável pela fixação da bactéria à mucosa da orofaringe, além de apresentar propriedade antifagocítica ${ }^{16,17}$.

\section{Epidemiologia}

Estima-se que aproximadamente 18 milhões de pessoas sejam acometidas por doenças graves ocasionadas por GAS que são responsáveis por 500 mil mortes/ano. Além disto, 1,7 milhões de novos casos ocorrem todo ano e por isso, as doenças causadas por estreptococos do grupo A, são consideradas um problema de saúde pública em países em desenvolvimento, com aproximadamente 600 milhões de casos/ano ${ }^{19}$.

A grande maioria destes casos ocorre em países não desenvolvidos, particularmente no continente Africano. A prevalência mais alta de DRC no mundo é encontrada na África sub-saariana (5.7 em cada 1000 crianças em fase escolar), e é estimado que mais de 1 milhão de crianças entre 5 e 14 anos são afetadas pela doença ${ }^{19,20}$. Na Índia, a prevalência da FR/DRC varia de 0,5 a 11/1000 indivíduos ${ }^{21}$.

A FR e a DRC estão frequentemente associadas às condições socioeconômicas que favorecem a difusão da bactéria pela falta de tratamento e condições sanitárias. Assim, apesar da reconhecida redução da incidência da FR nas últimas décadas nos países desenvolvidos, com conseqüente redução em sua prevalência, FR e DRC permanecem como um grande problema de saúde pública, principalmente nos países em desenvolvimento ${ }^{2}$.

No Brasil, a FR ainda representa a maior causa de doença cardíaca entre crianças e adultos jovens ${ }^{22}$. Segundo dado do Ministério da Saúde estima-se que a prevalência da FR em crianças e adolescentes seja de aproximadamente 3\%. A DRC é responsável por $30 \%$ das cirurgias cardíacas em adultos e $90 \%$ das cirurgias cardíacas infantis ${ }^{2}$. Os dados disponíveis no Brasil, a partir do sistema DATASUS, informam basicamente sobre internações hospitalares e intervenções, não correspondendo à totalidade dos casos diagnosticados no país. Estudos realizados na população de escolares em algumas capitais brasileiras estimaram a prevalência de DRC em 1-7 casos/1.000, o que é significativamente maior do que a prevalência da doença em países desenvolvidos, como nos Estados Unidos, onde varia entre 0,1-0,4 casos/1.000 escolares ${ }^{19,23}$.

Seguindo a projeção do modelo epidemiológico da OMS e de acordo com o último censo do Instituto Brasileiro de Geografia e Estatística (IBGE), estima-se que anualmente no Brasil ocorram cerca de 10 milhões de faringoamigdalites estreptocócicas, perfazendo o total de 30.000 novos casos de FR, dos quais aproximadamente 15.000 poderiam evoluir com acometimento cardíaco ${ }^{2}$.

A frequência da FR aguda no Brasil difere de acordo com a região geográfica, porém em todas as regiões observa-se uma redução progressiva do total de internações por esta doença. A taxa de mortalidade por DRC em pacientes internados pelo SUS foi de $6,8 \%$ em 2005 e de 7,5\% em 2007, com gasto aproximado no tratamento clínico de 52 milhões de reais em 2005 e de 55 milhões em 2007. Gastos de cerca de 94 milhões de reais em 2005 e de 100 milhões em 2007 em procedimentos intervencionistas, cirurgias e valvotomias percutâneas também foram direcionados ao tratamento das sequelas cardíacas da FR. Os gastos gerados pela assistência aos pacientes com FR e DRC no Brasil são altos. Em 2007, foram gastos pelo Sistema Único de Saúde (SUS) cerca de $R \$ 157.578 .000,00$ em internações decorrentes de FR ou DRC, de origem clínica ou cirúrgica, sendo que, das cirurgias cardíacas realizadas neste período, $31 \%$ abordaram pacientes com sequelas de FR. Na análise de morbidade, o cálculo do índice DALYs disability-adjusted life years (anos potenciais de vida perdidos ajustados para incapacidade) - demonstrou o total de 55 mil anos de vida perdidos em decorrência da FR, ou seja, 26 anos por paciente anualmente no 
De Amicis KM et al. Febre reumática - patogênese e vacina.

Brasil, baseado em dados do ano $2000^{2}$.

\section{Predisposição genética}

As sequelas não-supurativas autoimunes pósestreptocócicas podem se desenvolver tardiamente em indivíduos geneticamente predispostos ${ }^{1}$.

O MHC (complexo principal de histocompatibilidade) desempenha um papel central no desenvolvimento da resposta imune humoral e mediada por células. Enquanto os anticorpos são capazes de reagir sozinhos contra antígenos, as células $T$ em sua maioria reconhecem o antígeno somente quando está combinado com uma molécula do $\mathrm{MHC}$ que têm, portanto, um papel crítico no reconhecimento do antígeno pelas células $T$. Estas moléculas atuam como estruturas apresentadoras de antígenos, de forma que um grupo específico de moléculas do MHC expressas por um indivíduo influencia o repertório dos antígenos que serão reconhecidos pelas células $\mathrm{T}$, seguido de ativação celular. Por esta razão, o MHC determina a resposta de um indivíduo aos antígenos de organismos infecciosos, e tem sido relacionado com a suscetibilidade a doenças e com o desenvolvimento da autoimunidade ${ }^{24}$.

A suscetibilidade ao desenvolvimento da FRe $\mathrm{DRC}$ foi primeiramente associada com a presença de alelos do sistema HLA (do inglês - human leucocyte antigen) de classe II dos loci DRB1 e DRB3 localizados no braço curto do cromossomo 6 (revisto por Bryant et al. ${ }^{12}$ e Guilherme et al. ${ }^{25}$ ).

Os alelos HLA DR7 e DR53 estão associados ao desenvolvimento da FR e DRC em algumas populações no Brasil, Egito e Turquia ${ }^{26}$, tendo sido inicialmente descritos, em amostras da população brasileira ${ }^{27}$. Outros alelos HLA-DR e DQ foram posteriormente descritos em diferentes países ${ }^{12,26}$.

A Figura 1, localiza a distribuição dos alelos HLA associados com a FR/DRC. Mais recentemente, foram descritos polimorfismos em alguns genes não relacionados com o sistema HLA, envolvidos com a resposta inflamatória e defesa do hospedeiro (resposta inata e adaptativa) contra o S. pyogenes.

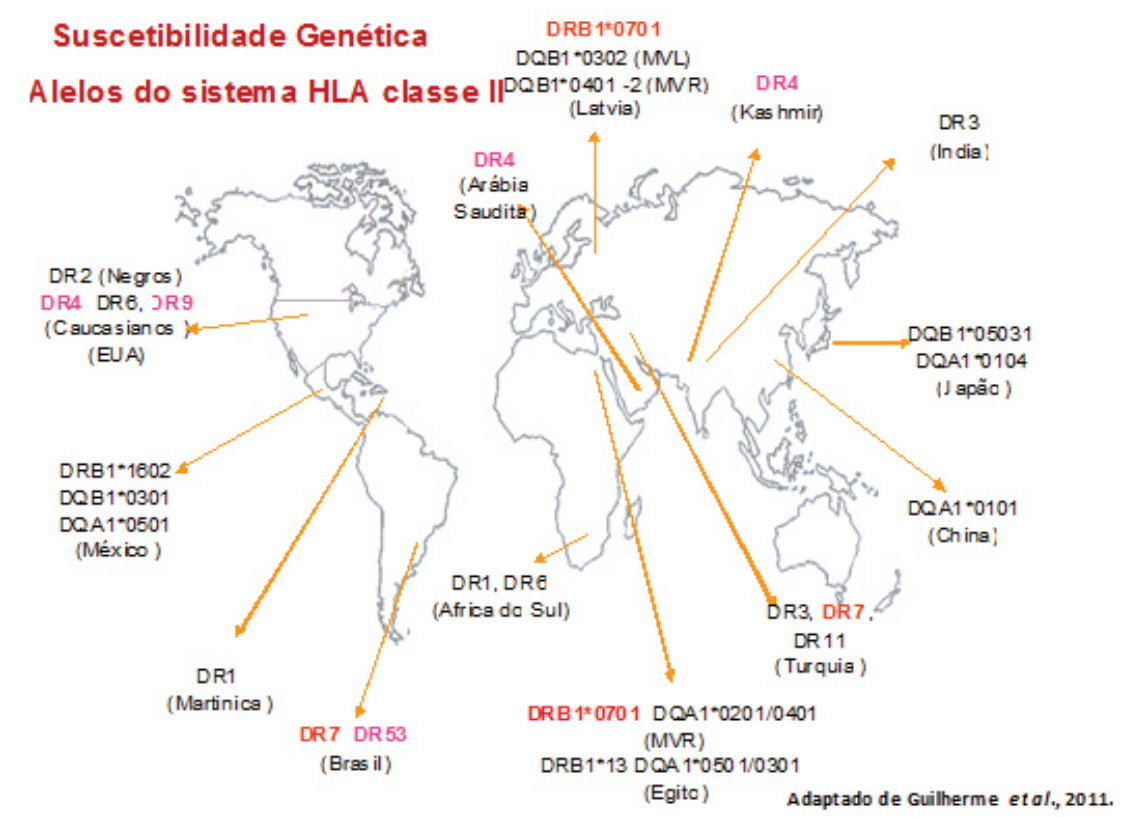

Figura 1. Alelos do sistema HLA de classe II associados ao desenvolvimento da Febre Reumática/Doença Reumática Cardíaca

Estudos na população brasileira acometida por FR/DRC mostraram o polimorfismo de SNP (do inglês "single nucleotide polymorphism" - polimorfismo de um único nucleotideo), no promotor do gene TNF (do inglês - tumor necrosis factor) - $\alpha$ estava associado ao desenvolvimento de lesões de valva aórtica ${ }^{28}$. Posteriormente, em estudo com genes do sistema complemento ${ }^{29}$, mostraram o polimorfismo no gene MBL-2 (do inglês - manose binding lectin), estando este associado à regurgitação de valva aórtica de origem reumática. Também é associado à gravidade da FR/DRC o polimorfismo do gene do receptor da IL-130.

Existem outros estudos de polimorfismo de genes em outras populações além da brasileira ${ }^{12,26}$. Todos os estudos descritos são importantes, uma vez que os polimorfismos dos genes envolvidos com a resposta imune podem fornecer informações preciosas, tais como a progressão da doença, bem como um possível alvo terapêutico. 


\section{Patogênes da FR e DRC}

O mimetismo molecular entre o $S$. pyogenes e as proteínas do tecido cardíaco foi demonstrado através da análise do repertório de células T infiltrantes do tecido cardíaco levando ao dano tecidual na $\mathrm{DRC}^{31}$.

No início da infecção ocorre a colonização do epitélio da orofaringe pelo patógeno e como consequência há a ativação da resposta imune inata. Macrófagos migram até o local de infecção e fagocitam o patógeno, e o microambiente gerado passam a ter o predomínio de citocinas pró-inflamatórias, com consequente ativação da resposta imune. Citocinas são fatores importantes durante a infecção, desencadeiam resposta imune efetiva, mas que pode ser deletéria em doenças autoimunes entre elas na FR/DRC. As células T CD4 ${ }^{+}$ativadas dependem diretamente das citocinas para polarizarem a resposta imune para diferentes padrões de resposta como Th1, Th2 e Th17, que envolvem diversas citocinas com atividades inflamatória, reguladora da inflamação e mediadoras de reações alérgicas. A infecção por $S$. pyogenes no estágio inicial, leva a uma reação inflamatória que envolve citocinas como a IL-1, IL-6 e TNF- $\alpha$, conforme descrito em amostras de sangue periférico de pacientes com FR/DRC estimuladas com antígenos do estreptococo produtoras de grandes quantidades destas citocinas pró-inflamatórias ${ }^{32}$, Figura 2.

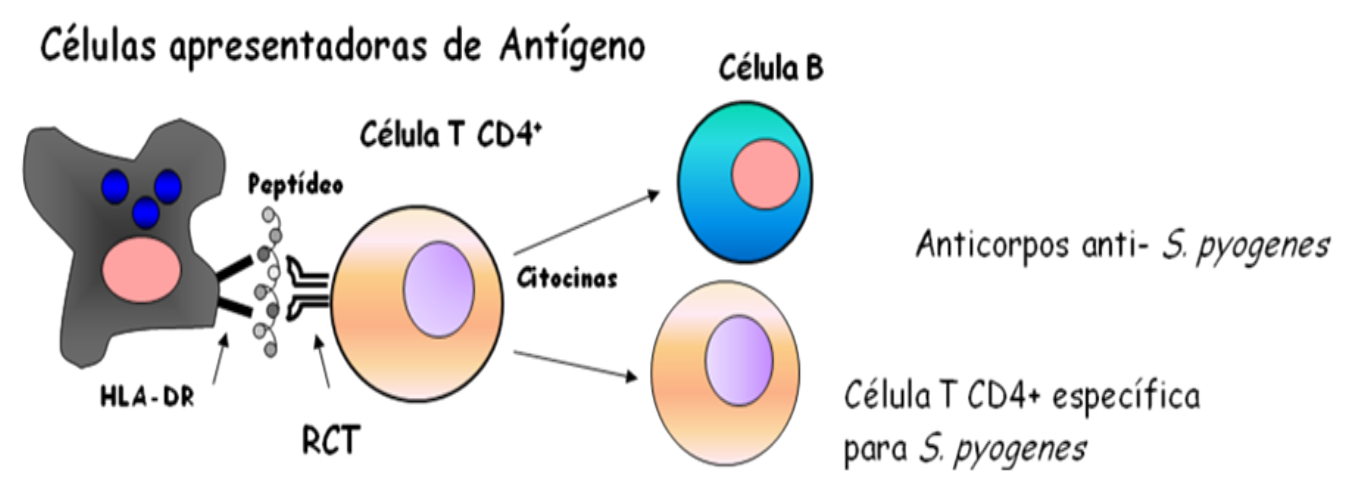

Figura 2. Representação esquemática da apresentação dos antigenos estreptocócios e a ativação da resposta imunológica. Os eventos que ocorrem durante a resposta imune adaptativa estão resumidos: 1) Reconhecimento da bactéria pelas células fagocíticas; processamento e apresentação do peptídeo para os linfócitos T; 2) Reconhecimento via RCT e mimetismo molecular; 3) Ativação da resposta imune adaptativa através da produção de citocinas pró-inflamatórias; 4) produção de anticorpos anti-S. pyogenes. (Adaptado de Guilherme et al., 2011) ${ }^{46}$.

As células $B$ ativadas produzem anticorpos autorreativos que se ligam ao endotélio do miocárdio e ao endotélio valvular facilitando a chegada de outras células até o local. Há um aumento da expressão da molécula de adesão VCAM1 que favorece a migração de células $T$ autorreativas principalmente para as válvulas ${ }^{33}$.

Em um estudo do nosso grupo foi observado pela primeira vez que $7,5 \%$ dos clones de células $T$ isolados de biópsias de lesões cardíacas de pacientes com DRC grave, possuem a habilidade de reconhecer simultaneamente peptídeos da proteína M e proteínas derivadas do tecido cardíaco ${ }^{34}$.

Na seqüência, foi definida a região imunodominante da proteína M5 (81-103), reconhecida pelas células mononucleares do sangue periférico (PBMC) e por clones de células $T$ intralesionais ${ }^{35}$. Três regiões da proteína M5 (resíduos 1-25, 81-103 e 163-176) reagem cruzadamente com muitas frações de proteínas cardíacas, a maioria delas é derivada de tecido valvular e apresentam massa molecular de 95-150, 43-65 e 30-43 kDa ${ }^{34}$.

Em modelos murinos, nos quais os camundon- gos são imunizados com miosina cardíaca intacta, células $T$ dos linfonodos reagiram cruzadamente com peptídeos sintéticos desenhados a partir de porções da proteína M5 que alinhados com a região M5 (81-103) reconhecida por células T intralesionais, reforçam a imunodominância desta região ${ }^{36}$.

Em estudos posteriores, foi mostrado que o reconhecimento de antígenos do $S$. pyogenes pelo linfócito $T$ desencadeia uma cascata de reações cruzadas $^{31,34,37}$ por mecanismo de espalhamento de epítopos e pela degeneracidade do reconhecimento. A habilidade das células T em reconhecer uma enorme gama de antígenos é importante para o repertório de células $T$, já que o receptor da célula $T$ (RCT) não sofre mutações somáticas como fazem os genes das cadeias variantes dos anticorpos. O mimetismo pode desencadear o processo de doença em um órgão alvo e levar a uma doença autoimune crônica através do espalhamento de epitopos ${ }^{38}$.

O mecanismo de espalhamento de epítopos (epitope spreading) é bem estabelecido e sabe-se que durante a resposta imune, a reatividade é induzida também a epítopos diferentes daqueles epítopos 
que deram origem a reação contra o patógeno ${ }^{39}$.

Foi observado também que células derivadas de lesão cardíaca de pacientes com DRC secretam predominantemente IFN- $\gamma$ e TNF- $\alpha$, indicando que mesmo durante a fase crônica da doença há o predomínio de resposta inflamatória ${ }^{40}$. Além disto, as citocinas IL-10 e IL-4 (Th2), reguladoras da resposta inflamatória, são produzidas por células infiltrantes do miocárdio de pacientes com DRC grave. No entanto, poucas células mononucleares infiltrantes de lesão de válvulas mitral e aórtica são capazes de produzir IL-4. Assim, a baixa produção de IL-4 pelas células de lesões valvares pode contribuir para a manutenção e progressão das lesões, enquanto no miocárdio, a maior frequência de células produtoras de IL-4, contribui para a cura da miocardite que ocorre após algumas semanas ${ }^{40}$. Estes achados ressaltam a importância do equilíbrio entre respostas Th1/ Th2, e influenciam o grau das lesões reumáticas cardíacas $^{14}$.

\section{Vacinas}

As doenças estreptocócicas e pós-estreptocócicas são consideradas um problema de saúde pública nos países em desenvolvimento, e geram altos gastos aos sistemas de saúde. Desta forma, a produção de uma vacina que proteja o indivíduo contra as cepas mais prevalentes é de grande importância.

Tradicionalmente, o tratamento de infecções estreptocócicas em profilaxia primária e secundária é feito com a administração de penicilina-benzatina, ou outros antibióticos e/ou sulfamidas por períodos longos em indivíduos alérgicos à penicilina. Nesse sentido, o desenvolvimento de uma vacina contra o $S$. pyogenes trará inúmeros benefícios, prevenindo não só infecções estreptocócicas, como seqüelas destas estreptococcias (glomerulonefrites e FR).

A alta capacidade imunogênica da proteína $M$, a torna o principal alvo de estudo para o desenvolvimento de uma vacina anti-S. pyogenes. Assim, a maioria das vacinas propostas até hoje são baseadas no uso da proteína $\mathrm{M}$ como indutora de imunidade protetora. Várias abordagens de vacina contra 0 GAS foram testadas ao longo dos anos, desde 1923 a presente data ${ }^{41,42}$. As primeiras vacinas propostas usavam a bactéria inteira inativada e foram abandonadas devido a reações adversas. Posteriormente, passou-se a usar a proteína $M$ inteira de cepas específicas até 1979 , porém os resultados não foram satisfatórios. Na década de 80 , novas abordagens foram introduzidas, em modelo de peptídeo sintético. Após, modelos com base na porção N-terminal (cepa-específica) foram introduzidos por metodologia de proteína recombinante, e as vacinas hexavalente e 26-valente, que continham os sorotipos mais prevalentes nos EUA, entraram em ensaios clínicos de fase I e II43. Paralelamente, novas abordagens para a definição de epitopos protetores e modelos de vacinas de peptídeo sintético foram idealizados, tanto baseados na região $\mathrm{N}$-terminal quanto na região C-terminal. Além disto, atualmente existem oito modelos de vacinas que são baseados em outros antígenos estreptocócicos que não a proteína M. Esta abordagem têm o intuito de evitar o mimetismo molecular com proteínas humanas ${ }^{41,44}$.

Considerando-se os altos custos sócioeconômicos envolvidos com a FR/DRC no Brasil e em países em desenvolvimento e com base nos conhecimentos adquiridos sobre a patogênese da DRC, iniciamos há aproximadamente 15 anos o processo de desenvolvimento de uma vacina eficaz contra o estreptococo beta hemolítico do grupo A, sem desencadear autoimunidade. A abordagem leva em consideração conceitos de como o sistema imune poderia ser mais eficiente na indução de resposta imune protetora via linfócitos T e B visando prevenir a adesão e invasão das células endoteliais da garganta, com conseqüente bloqueio da infecção local.

A vacina em desenvolvimento tem como base seqüências conservadas de aminoácidos da região C-terminal da proteína $\mathrm{M}$. Foi avaliada a reatividade humoral e celular de resíduos de aminoácidos da região C-terminal (aminoácidos 253 a 350) da proteína M5 do $S$. pyogenes, através da análise de 79 peptídeos sintéticos contendo 20 resíduos de aminoácidos compartilhados (variação de dois resíduos de aminoácidos nas extremidades) ${ }^{45}$.

Além disso, foi possível definir os epitopos imunodominantes de estimulação de células $\mathrm{B}$ e $\mathrm{T}$, respectivamente através de testes com mais de 600 amostras de soro humano e linfócitos de sangue periférico contra sequências da proteína $\mathrm{M}$. O epitopo $B$ é composto por uma seqüência de 22 resíduos de aminoácidos e o epitopo T por 25 resíduos de aminoácidos. Estes epitopos compartilham 16 resíduos de aminoácidos.

A partir da seleção dos epitopos de estimulação de células $T$ e $B$ em humanos, foi sintetizado um peptídeo de 55 resíduos, denominado "StreptInCor" (identificação médica), que contém os epitopos B e $\mathrm{T}$, ligados entre si por oito resíduos de aminoácidos, em conformidade com o segmento natural da proteína M.

Esta abordagem levou em consideração a afinidade do epitopo selecionado às moléculas de HLA de classe II tendo em vista a habilidade do epitopo de ativar células T via RCT. A ativação de células T estimula a ativação de células $B$ induzindo 
a produção de anticorpos com potencial protetor ${ }^{46}$. O StreptlnCor, agente vacinal na forma de peptídeo sintético, já foi testado em camundongos, utilizando-se como adjuvantes o hidróxido de alumínio e o adjuvante de Freund. Camundongos das linhagens BALB/c e Swiss apresentaram ótima resposta humoral contra o StreptInCor, independentemente do adjuvante utilizado, com alta produção de $\lg G$.

Camundongos transgênicos para as moléculas HLA de classe II DR2, DR4, DQ6 e DQ8 foram imunizados com StreptInCor, utilizando o adjuvante

\section{REFERÊNCIAS}

1. Cunningham MW. Pathogenesis of group $A$ streptococcal infections. Clin Microbiol Rev. 2000;13:470-511.

2. Barbosa PJB, Müller RE, Latado AL, Achutti AC, Ramos AIO, Weksler C EA. Diretrizes brasileiras para diagnóstico, tratamento e prevenção da febre reumática da Sociedade Brasileira de Cardiologia, da Sociedade Brasileira de Pediatria e da Sociedade Brasileira de Reumatologia. Arq Bras Cardiol. 2009;93(3 supl. 4):118.

3. Narula J, Chandrasekhar Y, Rahimtoola S. Diagnosis of active rheumatic carditis. The echoes of change. Circulation. 1999;100:1576-81.

4. Dajani AS AE, Bierman FZ, Bisno AL, Deny FW, Durack DT. Guidelines for the diagnosis of rheumatic fever. Jones criteria, 1992 update. Special Writing Group of the Committee on Rheumatic Fever, Endocarditis, and Kawasaki Disease of the Council on Cardiovascular Disease in the Young of the American Heart Association. JAMA. 1992;268:2069-73.

5. Narula J, Virmani R, Reddy K, Tandon R. Rheumatic fever. Washington: American Registry of Pathology; 1999.

6. Serrano Jr C, Timerman A, Stefanini E. Tratado de cardiologia SOCESP. São Paulo: SOCESP; 2009.

7. Lancefield RC. A serological differentiation of human and other groups of hemolytic Streptococci. J Exp Med. 1933;57:571-95.

8. Trabulsi LR, Alterthum F, Candeias JAN, Gompertz OF. Microbiologia. 3a ed. São Paulo: Atheneu; 1999.

9. Hertzén E, Johansson L, Kansal R, Hecht A, Dahesh S, Janos M, Nizet V, Kotb M, Norrby-Teglund A. Intracellular Streptococcus pyogenes in human macrophages display an altered gene expression profile. PLoS One. 2012;7:e35218.

10. Laarman A, Milder F, van Strijp J, Rooijakkers S. Complement inhibition by gram-positive pathogens: molecular mechanisms and therapeutic implications. J Mol Med (Berl). 2010;88:115-20.

11. Kwinn LA, Nizet V. How group A Streptococcus circumvents host phagocyte defenses. Future Microbiol. hidróxido de alumínio (Alum). A vacina candidata induziu altos títulos de IgG1 (Th2, dependente de IL-4) e IgG2a (Th1, dependente de IFN- $\gamma$ ) pelo período de um ano sem reatividade contra miosina cardíaca porcina purificada e extrato protéico de miocárdio humano. Não foi observada nenhuma reação adversa ou autoimune em vários órgãos analisados ${ }^{47}$.

Nos últimos 20 anos foi possível elucidar alguns mecanismos que medeiam a autoimunidade na FR e DRC e paralelamente, abriu-se a possibilidade do desenvolvimento de uma vacina que pode se tornar realidade em breve.

\section{7;2:75-84.}

12. Bryant PA, Robins-Browne R, Carapetis JR, Curtis N. Some of the people, some of the time: susceptibility to acute rheumatic fever. Circulation. 2009;119:742-53.

13. Guilherme L, Kalil J, Cunningham M. Molecular mimicry in the autoimmune pathogenesis of rheumatic heart disease. Autoimmunity. 2006;39:31-9.

14. Guilherme L, Kalil J. Rheumatic fever and rheumatic heart disease: cellular mechanisms leading autoimmune reactivity and disease. J Clin Immunol. 2010;30:17-23.

15. Lancefield RC. Current knowledge of type-specific $\mathrm{M}$ antigens of group A streptococci. J Immunol. 1962;89:307-13.

16. Bisno AL, Brito MO, Collins CM. Molecular basis of group A streptococcal virulence. Lancet Infect Dis. 2003;3:191200.

17. Fischetti VA, Parry DA, Trus BL, Hollingshead SK, Scott JR, Manjula BN. Conformational characteristics of the complete sequence of group A streptococcal M6 protein. Proteins. 1988;3:60-9.

18. Smeesters PR, McMillan DJ, Sriprakash KS. The streptococcal M protein: a highly versatile molecule. Trends Microbiol. 2010;18:275-82.

19. Carapetis JR, Steer AC, Mulholland EK, Weber M. The global burden of group A streptococcal diseases. Lancet Infect Dis. 2005;5:685-94.

20. Essop MR, Nkomo VT. Rheumatic and nonrheumatic valvular heart disease: epidemiology, management, and prevention in Africa. Circulation. 2005;112:3584-91.

21. Saxena A, Kumar RK, Gera RP, Radhakrishnan S, Mishra S, Ahmed Z, Pediatrics WGoPARFaCColAo. Consensus guidelines on pediatric acute rheumatic fever and rheumatic heart disease. Indian Pediatr. 2008;45:565-73.

22. Costa LP, Domiciano DS, Pereira RMR. Demographic, clinical, laboratorial, and radiological characteristics of rheumatic fever in Brazil: systematic review. Rev Bras Reumatol. 2009;49:617-22.

23. Xavier R, Nolasco M, Muller R, Santos M, Lima A, Lucas 
MC. Prefere: da informação à prevenção. Editorial Laranjeiras. 2004;1(4):61-3.

24. Goldsby RA, Kindt TJ, Osborne BA. Kuby - Imunologia. 4a ed. Rio de Janeiro: Revinter; 2002.

25. Guilherme L, Kohler KF, Kalil J. Rheumatic heart disease: mediation by complex immune events. Adv Clin Chem. 2011;53:31-50.

26. Guilherme L, Köhler KF, Postol E, Kalil J. Genes, autoimmunity and pathogenesis of rheumatic heart disease. Ann Pediatr Cardiol. 2011;4:13-21.

27. Guilherme L, Weidebach W, Kiss MH, Snitcowsky R, Kalil J. Association of human leukocyte class II antigens with rheumatic fever or rheumatic heart disease in a Brazilian population. Circulation. 1991;83:1995-8.

28. Ramasawmy R, Fae KC, Spina G, Victora GD, Tanaka AC, Palacios SA, Hounie AG, Miguel EC, Oshiro SE, Goldberg AC, Kalil J, Guilherme L. Association of polymorphisms within the promoter region of the tumor necrosis factor-alpha with clinical outcomes of rheumatic fever. Mol Immunol. 2007;44:1873-8.

29. Ramasawmy R, Spina GS, Fae KC, Pereira AC, Nisihara R, Messias Reason IJ, Grinberg M, Tarasoutchi F, Kalil J, Guilherme L. Association of mannose-binding lectin gene polymorphism but not of mannose-binding serine protease 2 with chronic severe aortic regurgitation of rheumatic etiology. Clin Vaccine Immunol. 2008;15:932-6.

30. Azevedo PM, Bauer R, Caparbo Vde F, Silva CA, Bonfa E, Pereira RM. Interleukin-1 receptor antagonist gene (IL1RN) polymorphism possibly associated to severity of rheumatic carditis in a Brazilian cohort. Cytokine. 2010;49:109-13.31.

31. Guilherme L, Dulphy N, Douay C, Coelho V, Cunha-Neto E, Oshiro SE, Assis RV, Tanaka AC, Pomerantzeff PM, Charron D, Toubert A, Kalil J. Molecular evidence for antigen-driven immune responses in cardiac lesions of rheumatic heart disease patients. Int Immunol. 2000;12:1063-74.

32. Guilherme L, Fae K, Oshiro SE, Kalil J. Molecular pathogenesis of rheumatic fever and rheumatic heart disease. Expert Rev Mol Med. 2005;7:1-15.

33. Cunningham MW. T cell mimicry in inflammatory heart disease. Mol Immunol. 2004;40:1121-7.

34. Guilherme L, Cunha-Neto E, Coelho V, Snitcowsky R, Pomerantzeff PM, Assis RV, Pedra F, Neumann J, Goldberg A, Patarroyo ME. Human heart-infiltrating T-cell clones from rheumatic heart disease patients recognize both streptococcal and cardiac proteins. Circulation. 1995;92:415-20.

35. Guilherme L, Oshiro SE, Faé KC, Cunha-Neto E, Renesto G, Goldberg AC, Tanaka AC, Pomerantzeff PM, Kiss MH, Silva C, Guzman F, Patarroyo ME, Southwood S, Sette A, Kalil J. T-cell reactivity against streptococcal antigens in the periphery mirrors reactivity of heartinfiltrating $T$ lymphocytes in rheumatic heart disease patients. Infect Immun. 2001;69:5345-51.
36. Cunningham MW, Antone SM, Smart M, Liu R, Kosanke S. Molecular analysis of human cardiac myosincross-reactive B- and T-cell epitopes of the group A streptococcal M5 protein. Infect Immun. 1997;65:391323.

37. Fae KC, da Silva DD, Oshiro SE, Tanaka AC, Pomerantzeff PM, Douay C, Charron D, Toubert A, Cunningham MW, Kalil J, Guilherme L. Mimicry in recognition of cardiac myosin peptides by heartintralesional T cell clones from rheumatic heart disease. J Immunol. 2006;176:5662-70.

38. McMahon EJ, Bailey SL, Castenada CV, Waldner $\mathrm{H}$, Miller SD. Epitope spreading initiates in the CNS in two mouse models of multiple sclerosis. Nat Med. 2005;11:335-9.

39. Sercarz EE, Lehmann PV, Ametani A, Benichou G, Miller A, Moudgil K. Dominance and crypticity of T cell antigenic determinants. Annu Rev Immunol. 1993;11:729-66.

40. Guilherme L, Cury P, Demarchi LM, Coelho V, Abel L, Lopez AP, Oshiro SE, Aliotti S, Cunha-Neto E, Pomerantzeff PM, Tanaka AC, Kalil J. Rheumatic heart disease: proinflammatory cytokines play a role in the progression and maintenance of valvular lesions. Am J Pathol. 2004;165:1583-91.

41. Pandey M, Batzloff MR, Good MF. Vaccination against rheumatic heart disease: a review of current research strategies and challenges. Curr Infect Dis Rep. 2012;14:381-90.

42. Steer AC, Batzloff MR, Mulholland K, Carapetis JR. Group A streptococcal vaccines: facts versus fantasy. Curr Opin Infect Dis. 2009;22:544-52.

43. McNeil SA, Halperin SA, Langley JM, Smith B, Warren A, Sharratt GP, Baxendale DM, Reddish MA, Hu MC, Stroop SD, Linden J, Fries LF, Vink PE, Dale JB. Safety and immunogenicity of 26-valent group a streptococcus vaccine in healthy adult volunteers. Clin Infect Dis. 2005;41:1114-22.

44. Steer AC, Law I, Matatolu L, Beall BW, Carapetis JR. Global emm type distribution of group A streptococci: systematic review and implications for vaccine development. Lancet Infect Dis. 2009;9:611-6.

45. Guilherme L, Faé KC, Higa F, Chaves L, Oshiro SE, Freschi de Barros S, Puschel C, Juliano MA, Tanaka AC, Spina G, Kalil J. Towards a vaccine against rheumatic fever. Clin Dev Immunol. 2006;13:125-32.

46. Guilherme L, Alba MP, Ferreira FM, Oshiro SE, Higa F, Patarroyo ME, Kalil J. Anti-group A streptococcal vaccine epitope: structure, stability, and its ability to interact with HLA class II molecules. J Biol Chem. 2011;286:6989-98.

47. Guerino MT, Postol E, Demarchi LM, Martins CO, Mundel LR, Kalil J, Guilherme L. HLA class II transgenic mice develop a safe and long lasting immune response against StreptInCor, an anti-group A streptococcus vaccine candidate. Vaccine. 2011;29(46):8250-6. 